\title{
Bite force estimates in juvenile Tyrannosaurus rex based on simulated puncture marks
}

\author{
Joseph E Peterson ${ }^{\text {Corresp., }}{ }^{1}$, Z. Jack Tseng ${ }^{2}$, Shannon Brink ${ }^{3}$ \\ 1 Department of Geology, University of Wisconsin Oshkosh, Oshkosh, Wisconsin, United States of America \\ Department of Integrative Biology and Museum of Paleontology, University of California Berkeley, Berkeley, California, United States of America \\ 3 Department of Geological Sciences, East Carolina University, Greenville, North Carolina, United States of America \\ Corresponding Author: Joseph E Peterson \\ Email address: petersoj@uwosh.edu
}

Background. Bite marks attributed to adult Tyrannosaurus rex have been subject to numerous studies. However, few bite marks attributed to $T$. rex have been traced to juveniles, leaving considerable gaps in understanding ontogenetic changes in bite mechanics and force, and the paleoecological role of juvenile tyrannosaurs in the late Cretaceous.

Methods. Here we present bite force estimates for a juvenile Tyrannosaurus rex based on mechanical tests designed to replicate bite marks previously attributed to a T. rex of approximately 13 years old. A maxillary tooth of the juvenile Tyrannosaurus specimen BMR P2002.4.1 was digitized, replicated in dental grade cobalt chromium alloy, and mounted to an electromechanical testing system. The tooth was then pressed into bovine long bones in various locations with differing cortical bone thicknesses at varying speeds for a total of 17 trials. Forces required to replicate punctures were recorded and puncture dimensions were measured.

Results. Our experimentally derived linear models suggest bite forces up to $5,641.19 \mathrm{~N}$ from cortical bone thickness estimated from puncture marks on an Edmontosaurus and a juvenile Tyrannosaurus. These findings are slightly higher than previously estimated bite forces for a juvenile Tyrannosaurus rex of approximately the same size as BMR P2002.4.1 but fall within the expected range when compared to estimates of adult T. rex.

Discussion: The results of this study offer further insight into the role of juvenile tyrannosaurs in late Cretaceous ecosystems. Furthermore, we discuss the implications for feeding mechanisms, feeding behaviors, and ontogenetic niche partitioning. 
1 Bite force estimates in juvenile Tyrannosaurus rex

2 based on simulated puncture marks

3

4

5

6

7

Joseph E. Peterson ${ }^{1}$, Z. Jack Tseng ${ }^{2}$, Shannon Brink ${ }^{3}$

${ }^{1}$ Department of Geology, University of Wisconsin Oshkosh, Oshkosh, WI, USA

${ }^{2}$ Department of Integrative Biology and Museum of Paleontology, University of California Berkeley, Berkeley, CA, USA

${ }^{3}$ Department of Geological Sciences, East Carolina University, Greenville, NC, USA

Corresponding Author:

Joseph Peterson ${ }^{1}$

800 Algoma Blvd, Oshkosh, WI, 54901, USA

Email address: petersoj@uwosh.edu

\section{Abstract}

Background. Bite marks attributed to adult Tyrannosaurus rex have been subject to numerous studies. However, few bite marks attributed to T. rex have been traced to juveniles, leaving considerable gaps in understanding ontogenetic changes in bite mechanics and force, and the paleoecological role of juvenile tyrannosaurs in the late Cretaceous.

Methods. Here we present bite force estimates for a juvenile Tyrannosaurus rex based on mechanical tests designed to replicate bite marks previously attributed to a T. rex of approximately 13 years old. A maxillary tooth of the juvenile Tyrannosaurus specimen BMR P2002.4.1 was digitized, replicated in dental grade cobalt chromium alloy, and mounted to an electromechanical testing system. The tooth was then pressed into bovine long bones in various locations with differing cortical bone thicknesses at varying speeds for a total of 17 trials. Forces required to replicate punctures were recorded and puncture dimensions were measured.

Results. Our experimentally derived linear models suggest bite forces up to 5,641.19 N from cortical bone thickness estimated from puncture marks on an Edmontosaurus and a juvenile Tyrannosaurus. These findings are slightly higher than previously estimated bite forces for a juvenile Tyrannosaurus rex of approximately the same size as BMR P2002.4.1 but fall within the expected range when compared to estimates of adult T. rex.

Discussion: The results of this study offer further insight into the role of juvenile tyrannosaurs in late Cretaceous ecosystems. Furthermore, we discuss the implications for feeding mechanisms, feeding behaviors, and ontogenetic niche partitioning.

\section{Introduction}


Bite mechanics and feeding habits of dinosaurs have long been debated. A variety of

40

41

42

43

44

methods have been proposed to determine bite mechanics and bite forces of members of

Dinosauria, including stegosaurs, ceratopsians and hadrosaurids (Weishampel, 1984; Bell et al., 2009; Reichel, 2010; Erickson et al., 2015), and more commonly, theropods (Rayfield et al., 2001; Rayfield et al., 2005; Rayfield et al., 2007; Gignac et al., 2010; Lautenschlager et al., 2013). The genus Tyrannosaurus rex and other tyrannosaurids have been the focus of many studies on dinosaur bite force and bite mechanics (Erickson et al., 1996; Meers, 2002; Barret and Rayfield, 2006; Bates and Falkingham, 2012; Gignac and Erickson, 2017; Rowe and Snively, 2021; Therrien et al., 2021). These studies have relied on several methods for estimating bite forces, including multi-body dynamic analysis (MDA) (Bates and Falkinham, 2012), finite element analysis (Rayfield et al., 2005; Rayfield et al., 2007; Maiorino et al., 2015), and actualistic studies.

However, bite force estimates have largely focused on adult specimens with few studies providing estimates for juveniles or subadult Tyrannosaurus rex, leaving a considerable gap in the understanding of tyrannosaur ontogenetic dietary partitioning and paleoecology. Bates and Falkingham (2012) based their bite force estimate of a late-stage juvenile T. rex on MDA, suggesting allometric growth in bite force from juvenile to adult. The juvenile specimen used in that study (BMR P2002.4.1) was also found to possess bite marks through the left maxilla and nasal. These have been interpreted as conspecific bites by Peterson et al. (2009) based on the strong correlation between the dimensions and spacing of the punctures and the dentition of BMR P2002.4.1 itself (Figure 1A-E). Similarly, Peterson and Daus (2019) identified feeding traces on a proximal caudal vertebra from an Edmontosaurus (BMR P2007.4.1) likely produced 
61 by a $T$. rex of a similar ontogenetic stage using similar deductive methods to Peterson et al.

62 (2009) (Figure 2A-E).

63 The presence of two sets of puncture marks attributable to a late-stage juvenile

64 Tyrannosaurus rex provides the opportunity to test previously derived juvenile $T$. rex bite force

65 estimates from multi-body dynamic analyses (Bates and Falkingham, 2012) with actualistic

66 methods (Gignac et al., 2010). Comparisons between the bite forces of adult and juvenile

67 Tyrannosaurus rex have the potential to reveal ontogenetic niche partitioning (Woodward et al.,

68 2020) and illuminate the impact of Tyrannosaurus rex ontogeny in terrestrial Cretaceous

69 ecosystems.

70

71 Materials \& Methods

72

Gignac et al. (2010) reported on bite marks in a specimen of Tenontosaurus tilletti that were attributed to Deinonychus antirrhopus, and designed indentation experiments to determine bite force estimates for D. antirrhopus. We applied similar methods to estimate the bite force for a juvenile Tyrannosaurus. Previous studies of BMR P2002.4.1 (“Jane”) and BMR P2007.4.1 (“Constantine") suggest that their respective bite marks were produced by a lateral maxillary

77 tooth of a juvenile to sub-adult tyrannosaur (Peterson et al., 2009; Peterson and Daus, 2019). The

78 trace on BMR P2002.4.1 penetrates through 7.5 mm of cortical bone, while the traces on BMR

79 P2007.4.1 penetrates through $0.4 \mathrm{~mm}$ of cortical bone. Both sets of puncture marks are

80 approximately 10-19 $\mathrm{mm}$ in length, and 4-9 $\mathrm{mm}$ in width (Peterson et al, 2009; Peterson and

81 Daus, 2019). To replicate these indentations, a lateral maxillary tooth of the juvenile

82 Tyrannosaurus specimen BMR P2002.4.1 was digitized and 3D printed. Triangulated laser

83 texture scans were conducted at the Department of Geology at the University of Wisconsin-

84 Oshkosh in Oshkosh, WI. Scans were made with a NextEngine 3D Laser Scanner, capturing data 
85 at seven scanning divisions in high definition $\left(2.0 \mathrm{k}\right.$ points $\left./ \mathrm{in}^{2}\right)$. Models were built with the

86 NextEngine ScanStudio HD Pro version 2.02 and finalized as an STL (stereolithograph) model

87 (Figure 3A). The STL file was then imported into Meshmixer (Autodesk, version 10.0.297), in

88 which the 'Make Solid' algorithm was utilized to prepare the model for printing by filling 'gaps'

89 in the model mesh as well as the removal of artifacts from the scanning process (Peterson and

90 Krippner, 2019). While the digitization process produced a tooth model of the same dimensions

91 as the original specimen, fine details such as denticles were lost in the digital processing. The

92 digital model of the tooth was then fused to a model of an adapter that allowed the 3D printed

93 model to be mounted onto the test frame (see below) using Geomagic Wrap (3D Systems, Cary,

94 NC). In order to produce a suitable tooth analog, the STL file was 3D printed in a dental grade

95 cobalt chromium alloy $[\mathrm{Co}(61.0), \mathrm{Cr}(25.0), \mathrm{Mo}(6.0), \mathrm{W}(5.0), \mathrm{Mn}(<1.0), \operatorname{Si}(<1.0), \mathrm{Fe}(<1.0)]$ with a

96 yield strength of 47,436 N/cm² (474.36 MPa) (Figure 3B) by the Argen corporation (San Diego,

$97 \mathrm{CA}$ ) to serve as a rigid model relative to the testing medium (i.e. cortical bone). The compressive

98 strength of the alloy model was higher than that of tooth enamel (384 MPa) and dentin (297

$99 \mathrm{MPa}$ (Willems et al., 1993). However, the differences in physical properties between the alloy

100 tooth model and tyrannosaur teeth were irrelevant for the purposes of this study since the fossil

101 bite marks suggest that tyrannosaur teeth were capable of producing bite marks in bone. In order

102 to ensure that the alloy model was capable of withstanding similar stresses, a dental grade cobalt

103 chromium alloy was chosen due to its high compressive strength and rigidity that would be

104 needed for the high vertical and compressive loading the model would endure during testing.

105 The dental grade cobalt chromium alloy tooth model was mounted to a Shimadzu AGS-X

106 Universal Electromechanical Test Frame (ETF) equipped with a 10kN load cell, interfaced with

107 the Shimadzu TrapeziumX software for data collection. Prior experiments on bite force 
108 determination have utilized bovine limb bones for their varying cortical thicknesses and

109 similarity in microstructure to dinosaurian elements (Erickson et al, 2002; Locke, 2004; Gignac

110 et al., 2010). While the elements under study include cranial and vertebral elements that may

111 differ in microstructure than limb elements, the comparable variance in cortical thickness makes

112 bovid limb elements suitable models for these experiments.

113 A fresh right bovine humerus and an in-tact left radius/ulna pair, sourced from a local

114 meat market were used for indent simulations. The bones had muscle and other soft tissue

115 removed, were kept frozen upon purchase and thawed overnight at room temperature before

116 testing proceeded. Epiphyses were left intact to reduce the possibility of creating microfractures

117 and compromising structural integrity during removal. Bones were covered with paper towels

118 soaked in Hank's Balanced Salt Solution (HBSS) between tests to maintain moisture. The bones

119 were secured to the lower stage of the ETF using a series of 1-inch width nylon straps. Testing

120 parameters including maximum allowed force $(10 \mathrm{kN})$, maximum displacement (ranging from 5-

$12145 \mathrm{~mm}$ depending on depth of the test location on specimen), and speed $(1 \mathrm{~mm} / \mathrm{s})$ were set. Bone

122 mechanical behavior is loading rate-dependent, with increasing strength at higher loading rates

123 (McElhaney 1966). We adopted a conservative load rate of $1 \mathrm{~mm} / \mathrm{s}$ following Gignac et al.

124 (2010), and additionally conducted a limited number of trials at the higher but physiologically

125 more realistic rate of $10 \mathrm{~mm} / \mathrm{s}(\mathrm{n}=3$ trials) (Erickson et al., 1996) as well as the machine-defined

126 limit of $16 \mathrm{~mm} / \mathrm{s}(\mathrm{n}=2$ trials) to assess the sensitivity of the estimated puncture forces as a factor

127 of load rate. The tooth model was then pressed into the bones in various locations with differing

128 cortical bone thicknesses to produce a total of 17 indents (Figure 4A, B). After each individual

129 test, the resulting indent was measured using Mitutoyo vernier calipers for depth, width, and

130 length to the nearest $0.02 \mathrm{~mm}$ before proceeding. We plotted load-displacement relationships of 
131 all trials runs and kept only trials with smooth curves as in Gignac et al. (2010); curves that

132 exhibited sudden drops in measured load indicate presence of fractures at and around the

133 indentation site, and those curves were excluded from subsequent analyses. Furthermore, trials

134 that exhibited any visible movements or shifts in the test specimen were excluded from

135 subsequent analysis. During multiple trials that occurred in close spatial proximity to each other

136 on the test bone specimens, we visually inspected the targeted puncture sites to make sure there

137 are no visible cracks on the surface before conducting each trial. Post-indent testing, all

138 specimens were scanned at $0.6 \mathrm{~mm}$ slice thickness using a GE Discovery 690 PET-CT scanner in

139 the University at Buffalo Clinical and Translational Science Institute Image Center (Figure 5).

140 To estimate the indentation forces required to make the specific puncture marks observed

141 on BMR P2007.4.1 and BMR P2002.4.1, we used linear regression to model the relationship

142 between per trial maximum recorded indentation force and puncture site cortical bone thickness,

143 as in Gignac et al. (2010). We then used the linear regression model to calculate the indentation

144 forces required to make puncture marks with the measured cortical thickness values from BMR

145 P2007.4.1 (0.4 mm) and BMR P2002.4.1 (7.5 mm). Additionally, we estimated the uncertainty

146 around the calculated indentation forces using 95\% confidence intervals around the linear

147 regression model equation. These calculations were conducted in the R programming

148 environment using the core functions $l m$ and predict.

149

150 Results

151 The trial data were analyzed using linear modeling of bovine specimen cortical thickness

152 and indentation force values and derived predictive formulae (1) with the full data set (force =

$153637.41 *$ cortical-thickness $\left.+860.62 ; \mathrm{R}^{2}=0.5361\right)$ and $(2)$ with fractured trial values excluded

$154\left(\right.$ force $=628.48^{*}$ cortical-thickness $\left.+555.72 ; \mathrm{R}^{2}=0.6346\right)($ Fig. 6A-B $)$. The full dataset predicts a 
155 force of $1,115.58 \mathrm{~N}$ for the indentation on BMR P2007.4.1 and 5,641.19N for the indentations on

156 BMR P2002.4.1; the fracture-excluded dataset predicts a force of $807.11 \mathrm{~N}$ for the indentation on 157 BMR P2007.4.1 and 5,269.31N on BMR P2002.4.1 (Table 1).

158 The resulting relationships between puncture force and cortical thickness at puncture site 159 in the additional trials at higher load speeds are consistent with those obtained from the $1 \mathrm{~mm} / \mathrm{s}$

160 trials. At $10 \mathrm{~mm} / \mathrm{s}$, cortical thicknesses ranging from 3.7 to $5.3 \mathrm{~mm}$ required forces of $2,930.4$ to $16110,448.6 \mathrm{~N}$. At $16 \mathrm{~mm} / \mathrm{s}$, a cortical thickness of $4.5 \mathrm{~mm}$ correlated with a puncture force of

$1623,248.8 \mathrm{~N}$, and a thickness of $9 \mathrm{~mm}$ correlated with 9,024.41 N.

163 The maximum force recorded by the $10 \mathrm{kN}$ load cell was $10,448.60 \mathrm{~N}$, and minimum

164782.93 N. Summary of each trial and raw force-displacement time series data are available as 165 supplemental data (S1). A video of one of the experimental trials (S2) and CT images of the 166 experimentally punctured cow elements (S3) are available on MorphoSource

167 (https://www.morphosource.org/Detail/ProjectDetail/Show/project id/1117).

168

169

170

171

172

173

174

175

176

177 178

\section{Discussion}

Estimated bite forces of adult Tyrannosaurus rex have yielded a wide range of results, and our study provides the first experimentally derived juvenile bite force estimates to contextualize the assessment of adult bite force estimates. Modelled muscle volume estimates for adult T. rex bite correspond to forces between 8,526 and 34,522 N (Barrett and Rayfield, 2006; Bates and Falkingham, 2012). However, estimates incorporating likely muscle fiber length produced results over 64,000 $\mathrm{N}$ for adult $T$. $\operatorname{rex}$ (Bates and Falkingham, 2018). Furthermore, the unique tooth morphology and arrangement in adult T. rex promote fine fragmentation of bone during osteophagy (Gignac and Erickson, 2017). Juvenile T. rex such as BMR P2002.4.1 have much narrower and blade-like tooth morphologies (Carr, 2020) and were unlikely to have been 
179 able to withstand similar bite forces at this ontogenetic stage. Bates \& Falkingham (2012)

180 estimated a maximum bite force for BMR P2002.4.1 at 2,400-3,850 N and hypothesized that

181 ontogenetic increases in bite force could indicate a change in dietary partitioning and feeding

182 behavior while approaching adulthood. Our experimentally derived linear models suggest bite

183 forces of 5,269.31 $\mathrm{N}$ to $5,641.19 \mathrm{~N}$ from cortical bone thickness estimated from puncture marks

184 on a juvenile Tyrannosaurus (BMR P2002.4.1). These results suggest indentation forces up to

$185235 \%$ of previous estimates for juveniles. However, the lack of serration denticles on the dental

186 grade cobalt alloy tooth model used in this study may slightly influence these results (Abler,

187 1992).

188 The testing equipment used in this study has a limit of 10,000 N. However, most of the

189 results were well below this limit, suggesting that mechanical limits of the equipment were not a

190 factor in the results. Furthermore, the load cell on the test frame is rated for 10,000 N, with a

191 built-in safety factor of $\sim 5 \%$ over the listed limit. Therefore, it is possible that the values at and

192 over 10,000 N may be truncated. To assess the effect of potential truncation bias on our linear

193 model estimates of indentation force, we repeated the analysis by excluding force values at and

194 over $10,000 \mathrm{~N}$; the resulting indentation force estimates for the fossilized bite marks vary by 16 -

$19517 \%$ (higher in the "Constantine" specimen with trimmed data, lower in the "Jane" specimen

196 with trimmed data). Conservative adjustment of all model-predicted indentation forces by a

197 factor of $17 \%$ on both ends still returns values higher than previous estimates $(4,373.53-4,682.19$

$198 \mathrm{~N}$ with $17 \%$ reduction vs. 2,400-3,850 N reported by Bates \& Falkingham).

199 The range of material properties present (not quantified) throughout the test samples may

200 be partially responsible for the variability in puncture forces measured at a given cortical

201 thickness, and explain the similar results obtained in this study using different puncture rates 
202 (i.e., higher loading rates at less stiff locations may result in similar required puncture forces as 203 low loading rates at stiffer locations on the bone sample). linear or near-linear initial portion, consistent with expectations from first principles of bone mechanics within the elastic region of a material force-displacement or stress-strain curve. In

207 208

contrast, all but three of the force-displacement curves exhibited no clear peak force/stress; instead, the bone puncture continued to enlarge with additional penetration depth, with oscillating force magnitudes (Figure 7) (Erickson et al., 2004; Gignac et al., 2010). While these results do not permit absolute determination of whether the bites studied were made with the animals' highest possible bite force, they do offer insight into the minimum boundary for the bite force capabilities of a late-stage juvenile Tyrannosaurus rex.

We observed that the irregularly shaped epiphyses of the bovine bone specimens

sometimes generated minor to substantial movements of the test specimen relative to the testing frame during bite trials, despite the use of nylon straps to secure the specimens. Test trials that exhibited visible movements of the bone were removed from data analysis, but it is likely that minute movements took place during some of the bite force experiments. Consequently, we did not discuss the bite force trials individually, and we instead relied on regression model derived values as more robust estimates of the bite force values used in our linear model-based estimates of bite force, which were in turn based on cortical bone thickness at puncture mark sites of fossil specimens. The possible movement of bone specimens during a given bite experiment is not an unrealistic factor in the actual feeding and predatory behavior being studied, as movements of multiple bodies are involved in generating puncture marks from agonistic or hunting behavior in predators. Future studies that include a more formalized consideration of potential multibody 
225 dynamics of a particular bite would provide further refinement on such bite force estimates. We

226 opted to maintain the unmodified state of bone specimens in our trials, rather than processing

227 those samples into standardized shapes (e.g., cubes, cylinders), in order to minimize inadvertent

228 damage to samples from cutting and to maximize the number of testing locations on each

229 specimen. As such, the flexure of specimens is considered alongside flexures of the components

230 of the testing frame itself as systematic errors in the study design that added variability to our

231 measured values. Accordingly, the reported findings should be considered in this context.

232 Another important caveat to keep in mind is that multiple puncture trials were conducted

233 in relatively close spatial proximity to each other on the test specimens (especially on the

234 humerus specimen; Fig. 4A). Although we visually inspected each target puncture site prior to

235 setting up each experimental trial to ensure there were no visible surface fractures, it is possible

236 that internal and/or micro- fractures not visible to us were present at certain puncture sites. We

237 diligently maintained specimen moisture during the experimental trials, thus minimizing the

238 increase in brittleness of the bone from dehydration. Nevertheless, the results should be

239 interpreted with this caveat in mind.

240 The tooth marks observed on BMR P2002.4.1 and BMR P2007.4.1 are Type 1 punctures

241 (Jacobsen, 1998; Tanke and Currie, 1998), described as "punctures (partial and full penetration)

242 are circular to oval in outline. In unhealed examples, plates of bone are folded down and

243 inwards into the puncture hole. The tooth/teeth are pushed into the bone and extracted with no

244 additional damage" (Jacobsen, 1998). Erickson and Olson (1996) note that the tooth marks most

245 attributed to T. rex are classified as Type 1 and Type 2 ("Transverse gouges, scores or tooth

246 drag imprints are elongate, gently curving lesions with ragged (or healing) margins" which are

247 also known as “pull and puncture”) (Erickson et al., 2004; Carr, 2020). 

(Buffetaut, 1983; Katsura, 2004; Peterson et al., 2009) and attributed to intraspecific fighting.

250

251

252 253 254 255 256 257 258 259 260 261

Intraspecific facial biting in crocodylians involves rapid single bites to the face with quick inertial movements (Kalin, 1939; Webb and Messel, 1977; Webb et al., 1983; Bramble and Wake, 1985; Lang, 1987; Cleuren and De Vree, 2000; Schwenk, 2000; Njau and Blumenschine, 2006; Hiiemae and Crompton, 2013). Moderate to severe injuries from interspecific and intraspecific aggression have also been observed in juvenile Cinereous Vultures (Aegypius monachus) and Griffon Vultures (Gyps fluvus) that were observed fighting over access to a carcass (Blanco et al., 1997).

Feeding behaviors in crocodylians involve similar sequences of biting and quick inertial movements (Cleuren and De Vree, 2000; Njau and Blumenschine, 2006; Noto et al., 2012). However, during feeding carcasses are commonly dismembered through more vigorous inertial movements such as "death-rolling" where the predator will spin its body along the longitudinal axis while gripping the carcass in its jaws (Schmidt, 1944; Attwell, 1959; Green, 1988; Njau and Blumenschine, 2006). This method of carcass reduction permits inertial feeding and often produces abundant and deep-penetrating tooth marks that are morphologically similar to Type 1 and Type 2 tooth marks observed in theropod dinosaurs (Njau and Blumenschine, 2006).

Bite marks and feeding traces attributed to theropod dinosaurs have been extensively studied (Fiorillo, 1991; Carpenter, 1998; Chure et al., 1998; Jacobsen, 1998; Tanke and Currie; 1998; Farlow and Holtz, 2002; Fowler and Sullivan, 2006; Happ, 2008; Bell and Currie; 2009; Peterson et al., 2009; Gignac et al., 2010; Peterson and Daus, 2019; Eberth and Currie, 2010; Hone and Rauhut; 2010; Hone and Watabe, 2010; Longrich et al., 2010; DePalma et al., 2013; Hone and Tanke, 2015; McLain, 2018; Drumheller et al., 2020). Whereas most studies discuss 
271 tooth marks attributable to adult theropods, the ability to observe multiple bitten specimens from

272 a juvenile offer further insight into potential ontogenetic shifts in diet and behavior (e.g.

273 Shroeder et al., 2021). Bite marks specifically attributable to intraspecific aggression in

274 theropods include Type 1 and Type 2 tooth marks to the maxilla, nasal, jugal, and dentary

275 (Tanke and Currie, 1998; Bell and Currie, 2009; Peterson et al., 2009). In crocodylians, these

276 injuries are produced during rapid biting motions directed at the face, which is covered in

277 relatively thin integument and tissues, requiring less resistance from muscle prior to striking

278 bone.

279 Alternatively, traces from feeding can occur in a wide variety of skeletal locations, and

280 the amount of soft tissue present at the time of the bite can have considerable ramifications for

281 the morphology of the bite mark. For example, the bitten caudal vertebra of BMR P2007.4.1 is

282 from the cranial-most part of the tail where substantial muscles such as the M. ilio-ischocaudalis

283 and M. caudiofemoralis longus would have been present in life (Snively and Russell, 2007;

284 Peterson and Daus, 2019). However, the punctures are present on the ventral surface of the

285 centrum, suggesting that the tyrannosaur was feeding after the haemal complexes and most of the

286 superficial hypaxial muscles and M. caudofemoralis longus had been removed (Peterson and

287 Daus, 2019). Despite the inferred later-stage feeding, the punctures on BMR P2007.4.1 still

288 penetrate approximately $5 \mathrm{~mm}$ in depth. Similar penetrating marks occur from crocodylians

289 during the disarticulation of a carcass (i.e. "death-rolling"). The modelled craniocervical

290 musculature of adult Tyrannosaurus rex (based on analysis of superficial muscular

291 reconstructions of the M. transversospinalis capitis, M. complexus, and M. longissimus capitis

292 superficialis) suggest rapid strikes and inertial feeding similar to what is seen in extant

293 archosaurs (Snively and Russell, 2007). Furthermore, Snively et al. (2014) confirmed these 
294 actions in birds, through observations of EMG and kinematics; chickens and eagles roll their 295 heads to vigorously shake small prey or tear flesh, respectively. Considering the high leverage

296 from the broad skulls of juvenile and adult $T$. rex, such behavior would likely have been utilized

297 for prey dismemberment analogous to crocodylian "death-rolling". As such, the feeding traces

298 present on BMR P.2007.4.1 may have been the result of dismemberment of the carcass by a 299 juvenile tyrannosaur.

300 These experimental reconstructions of the punctures present on BMR P2002.4.1 and 301 BMR P2007.4.1 suggest that late-stage juvenile and subadult tyrannosaurs were capable of 302 puncturing bone during feeding and intraspecific aggressive bouts despite the absence of the 303 large, blunt dental crowns of adults (Woodward et al., 2020). The tooth marks present on BMR 304 P2007.4.1 are consistent with feeding traces during dismemberment, possibly while a significant 305 amount of soft tissue was still present (Peterson and Daus, 2019). Alternatively, the facial 306 pathologies on BMR P2002.4.1 involved minimal tissue, thus a quicker, higher-inertia bite is 307 likely, consistent with intraspecific aggression as seen in crocodylians (Njau and Blumenschine, 308 2006; Peterson et al., 2009). Further identification of tyrannosaur feeding traces from different 309 ontogenetic stages may reveal more insight into the ecological role and potentially dynamic 310 dietary trends of Tyrannosaurus rex throughout ontogeny.

\section{Acknowledgements}

313 The authors thank PeerJ Editor Andrew Farke, and reviewers Eric Snively, Lloyd

314 Courtenay, and Stephanie Drumheller for their helpful comments and suggestions. We thank

315 William W. Brink for laboratory assistance during experimentation trials, Jonathan P. Warnock,

316 Christopher R. Noto, and M. Allison Stegner for stimulating discussion in the experimental

317 design and constructive feedback on an early version of this manuscript. We also thank Moriarty 
318 Meats (1650 Elmwood Ave, Buffalo, NY 14207) for sourcing bone samples, and Paul Cascone

319 and the Argen Corporation for assisting in the production of the dental grade cobalt chromium

320 alloy tooth model used in this study.

321

322

323

324

325

326

327

328

329

330

331

332

333

334

335

336

337

338

339

340

341

342

343

344

345

346

347

348

349

350

351

352

353

354

355

356

357

358

\section{References}

Abler, WL. 1992. The serrated teeth of tyrannosaurid dinosaurs, and biting structures in other animals. Paleobiology. 18(2):161-183.

Attwell RIG. 1958. Crocodiles at Carion. Afr. Wildl. 13:13-22.

Barrett P. and Rayfield E. 2006. Ecological and evolutionary implications of dinosaur feeding behaviour. Trends. Ecol. Evol. 21:217-224.

Bates KT and Falkingham PL. 2012. Estimating maximum bite performance in Tyrannosaurus rex using multi-body dynamics. Biol. Letters. 8:660-664.

Bates KT and Falkingham PL. 2018. The importance of muscle architecture in biomechanical reconstructions of extinct animals: a case study using Tyrannosaurus rex. J. Anat. 233:625-635.

Bell PR and Currie PJ. 2009. A tyrannosaur jaw bitten by a confamilial: scavenging or fatal agonism? Lethaia. 43:278-281.

Bell PR, Snively E, and Shychoski LA. 2009. Comparison of the jaw mechanics in hadrosaurid and ceratopsid dinosaurs using finite element analysis. Anat. Rec. 292:1338-1351.

Blanco G, Traverso JM, Marchamalo J, and Martinez F. 1997. Interspecific and intraspecific aggression among Griffon and Cinereous Vultures at nesting and foraging sites. J. Raptor. Res. 31:77-79.

Bramble DM and Wake D. 1985. Feeding mechanisms of lower tetrapods. In: Hildebrand M, Bramble D, Liem K, and Wake D, eds. Functional Vertebrate Morphology. Cambridge: Harvard University Press, 230-261.

Buffetaut E. 1983. Wounds on the jaw of an Eocene mesosuchian crocodilian as possible evidence for the antiquity of crocodilian intraspecific fighting behaviour. PalZ. 57:143-145.

Carpenter K. 1998. Evidence of predatory behavior by carnivorous dinosaurs. Gaia. 15:135-144.

Carr TD. 2020. A high-resolution growth series of Tyrannosaurus rex obtained from multiple lines of evidence. PeerJ. 8, 9192; 10.7717/peerj.9192. 
359 Chure D.J, Fiorillo AR, and Jacobsen A. 1998. Prey bone utilization by predatory dinosaurs in 360 the Late Jurassic of North America, with comments on prey bone use by dinosaurs throughout

361

362

363

364

365

366

367

368

369

370

371

372

373

374

375

376

377

378

379

380

381

382

383

384

385

386

387

388

389

390

391

392

393

394

395

396

397

398

399

400

401

402

403

404
Cleuren J and De Vree F. 2000. Feeding in crocodilians. In: Schwenk K, ed. Feeding: Form, Function, and Evolution in Tetrapod Vertebrates. San Diego: Academic Press, 337-358.

DePalma RA, Burnham DA, Martin LD, Rothschild BM, and Larson PL. 2013. Physical evidence of predatory behavior in Tyrannosaurus rex. P. Natl. Acad. Sci. USA. 110:1256012564.

Drumheller SK, McHugh JB, Kane M, Riedel A, and D'Amore DC. 2020. High frequencies of theropod bite marks provide evidence for feeding, scavenging, and possible cannibalism in a stressed Late Jurassic ecosystem. Plos. One. 15, 0233115; 10.1371/journal.pone.0233115.

Eberth DA and Currie PJ. 2010. Stratigraphy, sedimentology, and taphonomy of the

Albertosaurus bonebed (upper Horseshoe Canyon Formation; Maastrichtian), southern Alberta, Canada. Can. J. Earth. Sci. 47:1119-1143.

Erickson GM and Olson KH. 1996. Bite marks attributable to Tyrannosaurus rex: preliminary description and implications. J. Vertebr. Paleontol. 16:175-178.

Erickson GM, Van Kirk SD, Su J, Levenston ME, Caler WE, and Carter DR. 1996. Bite-force estimation for Tyrannosaurus rex from tooth-marked bones. Nature. 382:706-708.

Erickson GM, Sidebottom MA, Kay DI, Turner KT, Ip N, Norell MA, Sawyer WG, and Krick BA. 1996. Wear biomechanics in the slicing dentition of the giant horned dinosaur Triceratops. Sci. Adv. 1, 1500055; 10.1126/sciadv.1500055.

Erickson GM, Catanese J III, and Keaveny T. 2002. Evolution of the biomechanical material properties of the femur. Anat. Rec. 268:115-124.

Erickson GM, Lappin AK, Parker T, and Vliet KA. 2004. Comparison of bite-force performance between long-term captive and wild American alligators (Alligator mississippiensis). J. Zool. 262:21-28.

Farlow JO and Holtz TR. 2002. The fossil record of predation in dinosaurs. The Paleontological Society Papers 8:251-266.

Fiorillo AR. 1991. Prey bone utilization by predatory dinosaurs. Palaeogeogr. Palaeoclimatol. Palaeoecol. 88:157-166.

Fowler DW and Sullivan RWM. 2006. A ceratopsid pelvis with toothmarks from the Upper Cretaceous Kirtland Formation, New Mexico: evidence of late Campanian tyrannosaurid feeding behavior. New Mexico Museum of Natural History and Science Bulletin. 35:127-130. 
405 Gignac PM and Erickson GM. 2017. The biomechanics behind extreme osteophagy in

406 Tyrannosaurus rex. Sci. Rep. 7, 2012. doi.org/10.1038/s41598-017-02161-w.

407

408

409

410

411

412

413

414

415

416

417

418

419

420

421

422

423

424

425

426

427

428

429

430

431

432

433

434

435

436

437

438

439

440

441

442

443

444

445

446

447

448

449

450

Gignac PM, Makovicky PJ, Erickson GM, and Walsh RP. 2010. A description of Deinonychus antirrhopus bite marks and estimates of bite force using tooth indentation simulations. J. Vertebr. Paleontol. 30:1169-1177.

Green J. 1988. Crocodile 1: Go ahead make his day. Geo. 9:17-29.

Happ J. 2008. An analysis of predator-prey behavior in a head-to head encounter between Tyrannosaurus rex and Triceratops. In: Larson P and Carpenter K, eds. Tyrannosaurus rex the Tyrant King. Bloomington: Indiana University, 352-370.

Hiiemae KM and Crompton AW. 2013. Mastication, food transport and swallowing. In: Hildebrand M, Bramble D, Liem K, and Wake D, eds. Functional Vertebrate Morphology. Cambridge: Harvard University Press, 262-290.

Hone DWE and Tanke DH. 2015. Pre- and postmortem tyrannosaurid bite marks on the remains of Daspletosaurus (Tyrannosaurinae: Theropoda) from Dinosaur Provincial Park, Alberta, Canada. PeerJ. 3, 885; 10.7717/peerj.885.

Hone DWE and Watabe M. 2010. New information on the scavenging and selective feeding behavior of tyrannosaurids. Acta. Paleontol. Pol. 55:627-634.

Hone DWE and Rauhut OWM. 2010. Feeding behaviour and bone utilisation by theropod dinosaurs. Lethia. 43:232-244.

Jacobsen AR. 1998. Feeding behaviour of carnivorous dinosaurs as determined by tooth marks on dinosaur bones. Hist. Biol. 13:17-26.

Kalin JA. 1936. Uber Skeletanomalien der Crocodilien: Zeitschrift fur Morphologie und Oekologie de Tiere 32 :327-347.

Katsura Y. 2004. Paleopathology of Toyotamaphimeia machikanensis (Diapsida, Crocodylia) from the middle Pleistocene of central Japan. Hist. Biol. 16:93-97.

Lang W. 1987. Crocodilian behavior: implications for management. In: Webb GJW, Manolis SC, and Whitehead PJ, eds. Wildlife Management: Crocodiles and Alligators. Syndey: Surrey Beatty, 273-294.

Lautenschlager S, Witmer LM, Altangerel P, and Rayfield EJ. 2013. Edentulism, beaks, and biomechanical innovations in the evolution of theropod dinosaurs. P. Nat. Acad. Sci. 110:20657-20662.

Locke M. 2004. Structure of long bones in mammals. Journal of Morphology. 262:546-565. 
451 Longrich NR, Horner JR, Erickson GM, and Currie PJ. 2010. Cannibalism in Tyrannosaurus rex. 452 Plos. One. 5, 0012314; 10.1371/journal.pone.0013419.

453

454

455

456

457

458

459

460

461

462

463

464

465

466

467

468

469

470

471

472

473

474

475

476

477

478

479

480

481

482

483

484

485

486

487

488

489

490

491

492

493

494

495

496

Maiorino L, Farke AA, Kotsakis T, Teresi L, and Piras P. 2015. Variation in the shape and mechanical performance of the lower jaws in ceratopsid dinosaurs (Ornithischia, Ceratopsia). J. Anat. 227:631-646.

McElhaney JH. 1966. Dynamic response of bone and muscle tissue. J. Appl. Physiol. 21:12311236.

McLain MA, Nelsen D, Snyder K, Griffin CT, Siviero B, Brand LR, and Chadwick AV. 2018. Tyrannosaur cannibalism: a case of a tooth-traced tyrannosaurid bone in the Lance Formation (Maastrichtian), Wyoming. Palaios. 33:164-173.

Meers MB. 2002. Maximum bite force and prey size of Tyrannosaurus rex and their relationships to the inference of feeding behavior. Hist. Biol. 16:1-12.

Njau JK and Blumenschine RJ. 2006. A diagnosis of crocodile feeding traces on larger mammal bone, with fossil examples from the Plio-Pleistocene Olduvai Basin, Tanzania. J. Hum. Evol. $50: 142-162$.

Noto CR, Main DJ, and Drumheller SK. 2012. Feeding traces and paleobiology of a Cretaceous (Cenomanian) crocodyliform: example from the Woodbine Formation of Texas. Palaios. 27:105115.

Peterson JE and Daus KN. 2019. Feeding traces attributable to juvenile Tyrannosaurus rex offer insight into ontogenetic dietary trends. PeerJ. 7,6573; 10.7717/peerj.6573.

Peterson JE and Krippner ML. 2019. Comparisons of fidelity in the digitization and 3D printing of vertebrate fossils. Journal of Paleontological Techniques. 22:1-9.

Peterson JE, Henderson MD, Scherer RP, and Vittore CP. 2009. Face biting on a juvenile tyrannosaurid and behavioral implications. Palaios. 24:780-784.

Rayfield EJ. 2005. Aspects of comparative cranial mechanics in the theropod dinosaurs Coelophysis, Allosaurus and Tyrannosaurus. Zool. J. Linn Society. 144:309-316.

Rayfield EJ, Norman DB, Horner CC, Horner JR, Smith PM, Thomason JJ, and Upchurch P. 2001. Cranial design and function in a large theropod dinosaur. Nature. 409:1033-1037.

Rayfield EJ, Milner AC, Xuan VB, and Young PG. 2007. Functional morphology of spinosaur 'crocodile-mimic' dinosaurs. J. Vertebr. Paleontol. 27:892-901.

Reichel MA. 2010. Model for the bite mechanics in the herbivorous dinosaur Stegosaurus (Ornithischia, Stegosauridae). Swiss. J. Geosci. 103:235-240.

PeerJ reviewing PDF | (2021:03:58983:2:0:NEW 21 Apr 2021) 
497 Rowe AJ and Snively E. 2021. Biomechanics of juvenile tyrannosaurid mandibles and their

498

499

500

501

502

503

504

505

506

507

508

509

510

511

512

513

514

515

516

517

518

519

520

521

522

523

524

525

526

527

528

529

530

531

532

533

534

535

536

537

538

539

540

541

implications for bite force. Anatomical Record. doi.10.1002/ar.24602.

Schimdt KP. 1944. Crocodiles. Fauna. 6:67-72.

Schroeder K, Lyons SK, and Smith FA. 2021. The influence of juvenile dinosaurs on community structure and diversity. Science 371.6532: 941-944.

Schwenk K. 2000. An introduction to tetrapod feeding. In: Schwenk K, ed. Feeding: Form, Function, and Evolution in Tetrapod Vertebrates. San Diego: Academic Press, 21-61.

Sharir A, Barak MM, and Shahar R. 2008. Whole bone mechanics and mechanical testing. The Veterinary Journal. 177:8-17.

Snively E and Russell AP. 2007. Functional morphology of neck musculature in the Tyrannosauridae (Dinosauria, Theropoda) as determined via a hierarchical inferential approach. Zool. J. Linn. Soc-London. 151:759-808.

Snively E, Russell AP, Powell GL, Theodor JM, and Ryan MJ. 2014. The role of the neck in the feeding behavior of the Tyrannosauridae: inference based on kinematics and muscle function of extant avians. Journal of Zoology 292:290-303.

Tanke DH andCurrie PJ. 1998. Head-biting behavior in theropod dinosaurs: paleopathological evidence. Gaia. 15:167-184.

Therrien F, Zelenitsky DK, Voris JT, and Tanaka K. 2021. Mandibular force profiles and tooth morphology in growth series of Albertosaurus sarcophagus and Gorgosaurus libratus (Tyrannosauridae: Albertosaurinae) provide evidence for an ontogenetic dietary shift in tyrannosaurids. Canadian Journal of Earth Science. doi.org/10.1139/cjes-2020-0177.

Webb G and Messel H. 1977. Abnormalities and injuries in the estuarine crocodile Crocodylus porosus. Wildlife. Res. 4:311-391.

Webb G, Manolis S, and Buckworth R. 1983. Crocodylus johnstoni in the McKinlay River area N.T, V. Abnormalities and injuries. Wildlife. Res. 10:407-420.

Weishampel DB. 1984. Ornithopod jaw mechanics. In: Weishampel DB, ed. Evolution of Jaw Mechanisms in Ornithopod Dinosaurs. Advances in Anatomy Embryology and Cell Biology 87. Berlin: Springer Heidelberg.

Willems G, Lambrechts P, Braem M, Vanherle G. 1993. Composite resins in the 21st century. Quintessence Int. 24(9):641-58.

Woodward HN, Tremaine K, Williams SA, Zanno LE, Horner JR, and Myhrvold N. 2020.

Growing up Tyrannosaurus rex: osteohistology refutes the pygmy "Nanotyrannus" and supports

PeerJ reviewing PDF | (2021:03:58983:2:0:NEW 21 Apr 2021) 
542 ontogenetic niche partitioning in juvenile Tyrannosaurus. Sci. Adv. 6, 6250;

543 10.1126/sciadv.aax6250.

544 
Figure 1

Lesions present on the face of BMR P2002.4.1.

A) A line drawing of the lesions (1-4). B) Red arrows indicate the locations of the four lesions on the left maxilla and nasal of BMR P2002.4.1. C) A dorsal view of the anterior nasal, with the red arrow indicating asymmetry resulting from the puncture on the left side. D) The first puncture (arrow 5 lesion 1) located on the articular surface of the anterior nasal and left maxilla. E) The three lesions on the left maxilla of BMR P2002.4.1 with a close-up of lesion 4 (F). Scale bars: A-B $510 \mathrm{~cm}$; C-E $55 \mathrm{~cm}$. Figure modified from Peterson et al., 2009. 


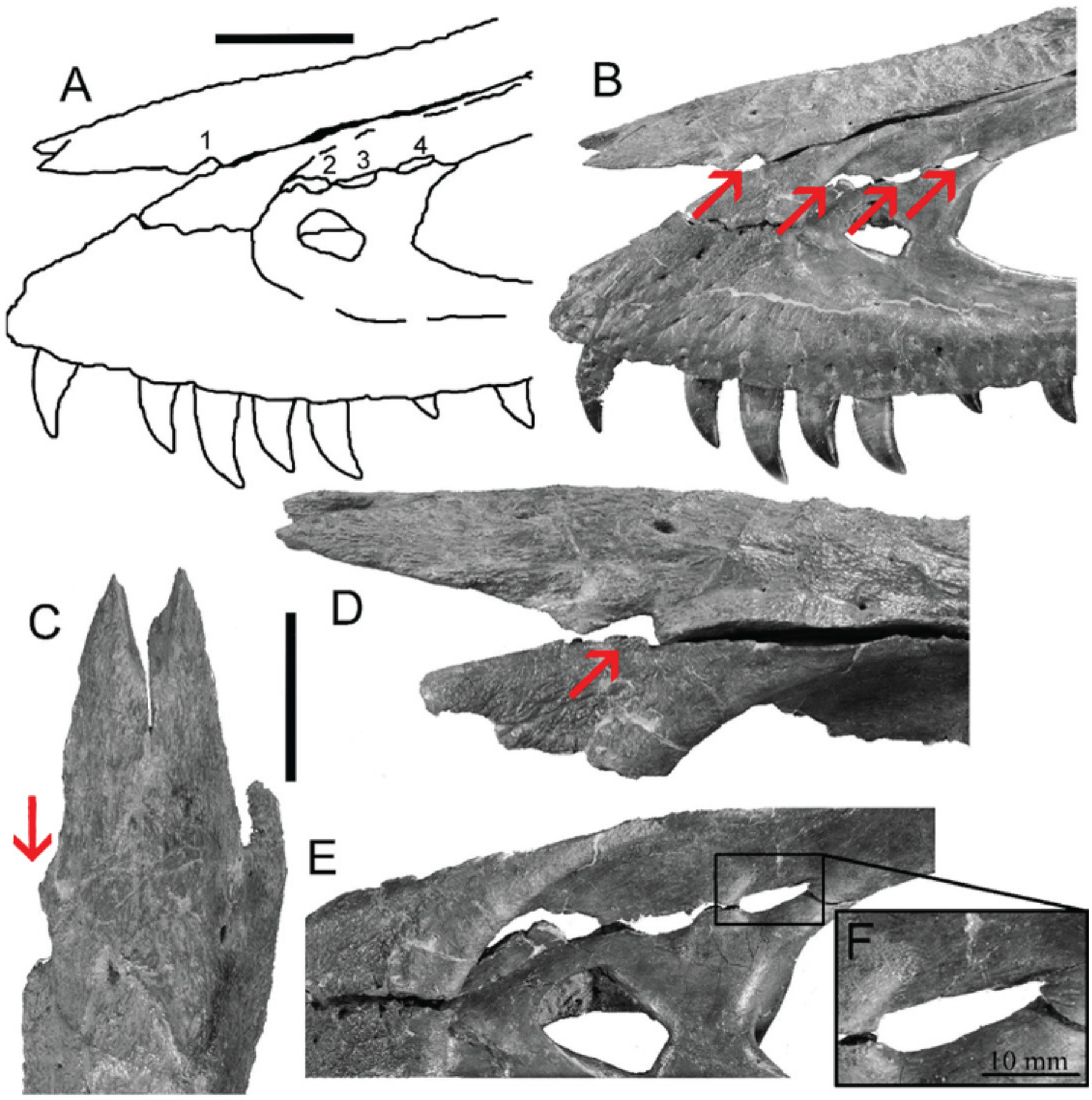


Figure 2

Punctured caudal vertebra of BMR P2007.4.1.

Punctured caudal vertebra of BMR P2007.4.1. BMR P2007.4.1 in (A) anterior, (B) posterior, and $(C)$ ventral views, including $(D, E)$ the two elliptical punctures on the ventral surface of the centrum. Modified from Peterson and Daus, 2019. 


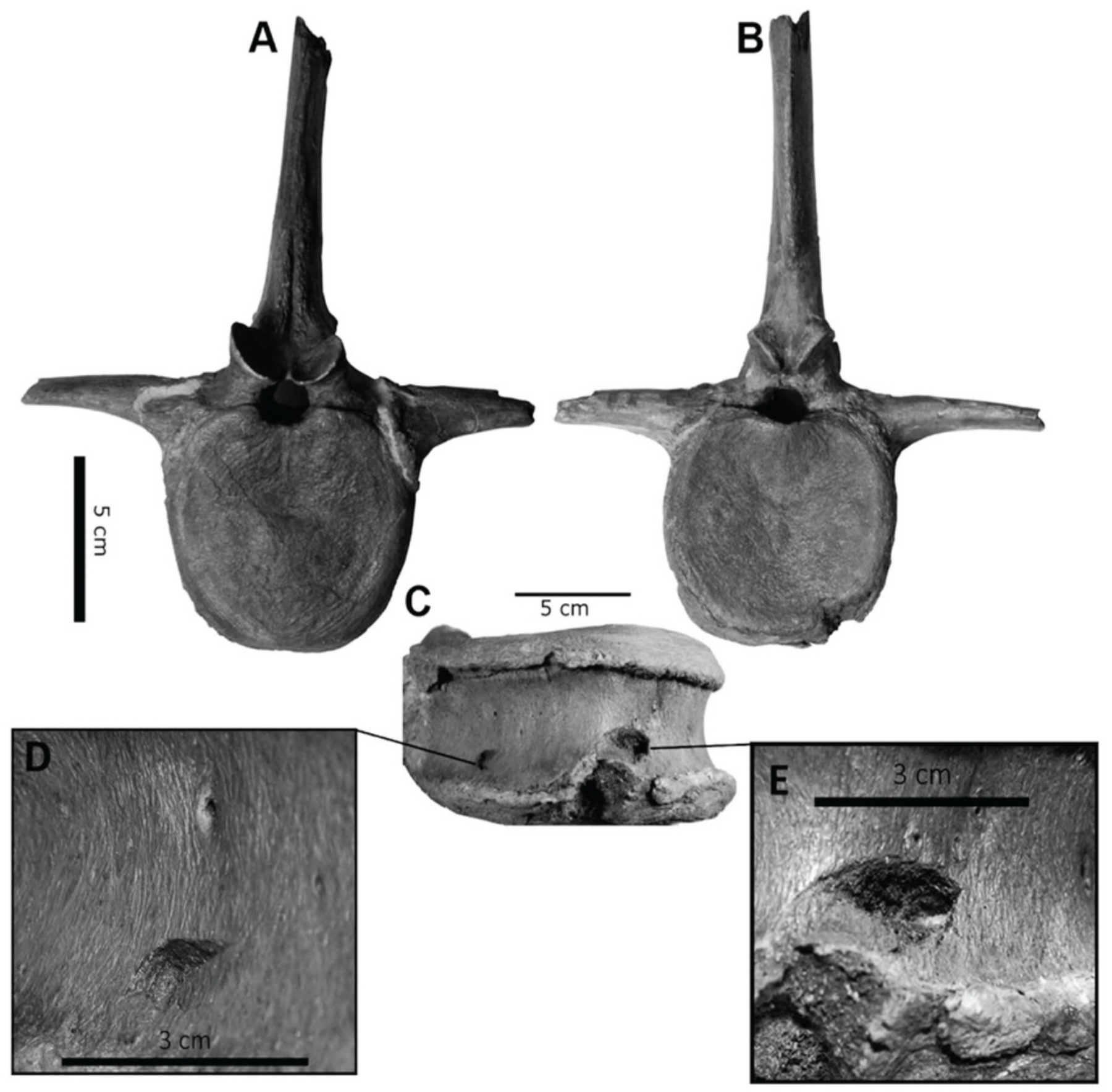


Figure 3

Maxillary tooth model of BMR P2002.4.1.

A) digital model, and B) 3D print in cobalt used for bite force simulation experiments.

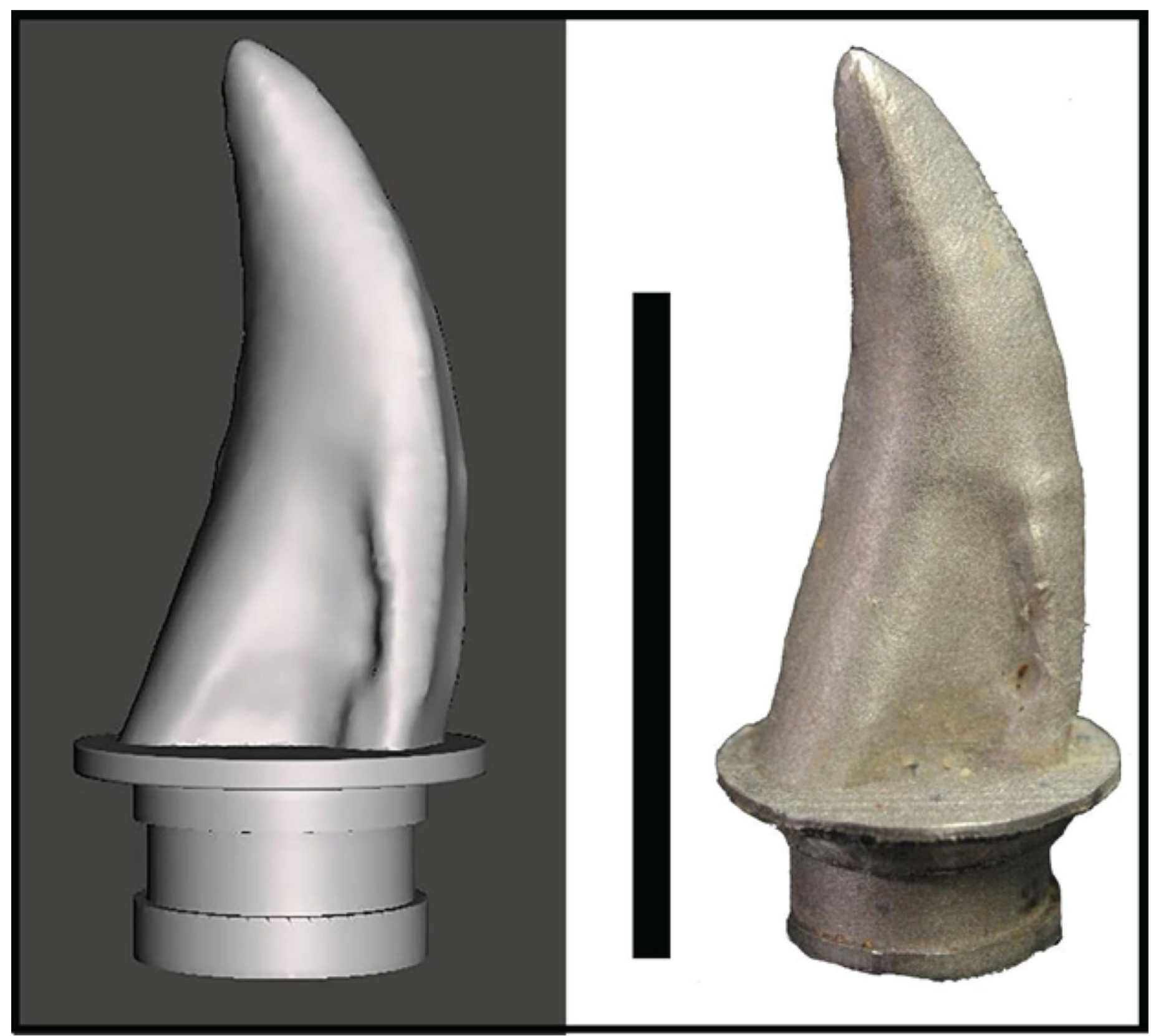


Figure 4

Spatial maps showing experimental indentation locations on bovine long bones.

A) Right humerus, B) left radius and ulna.

A

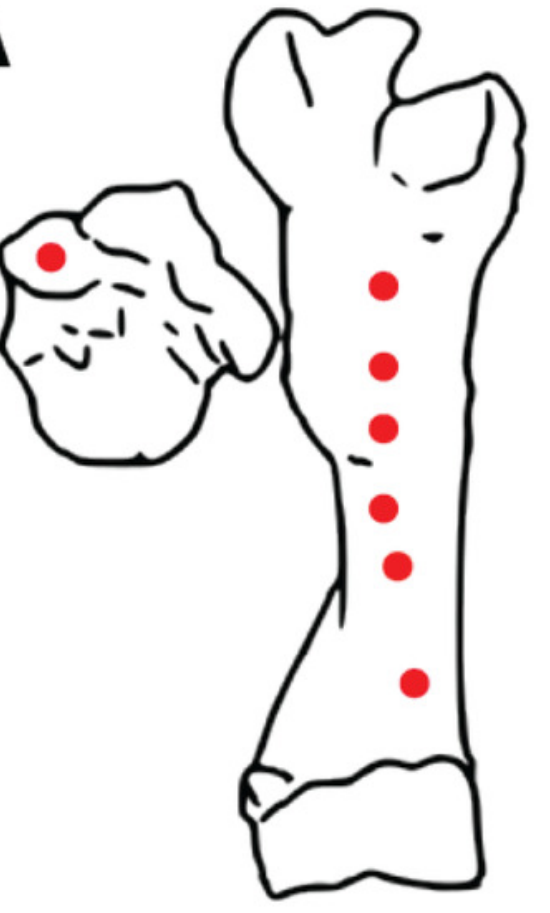

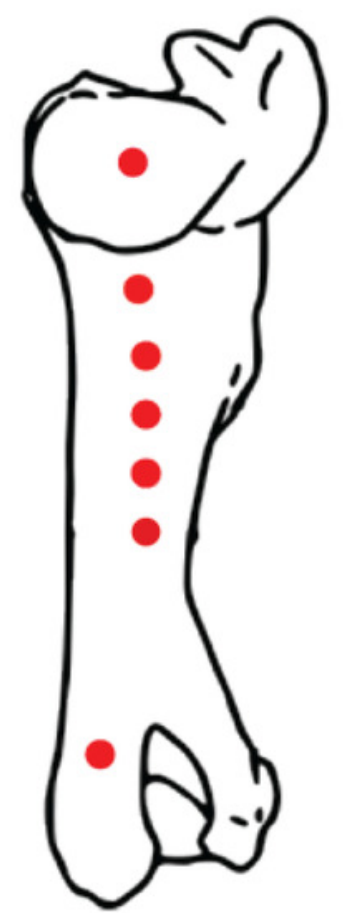
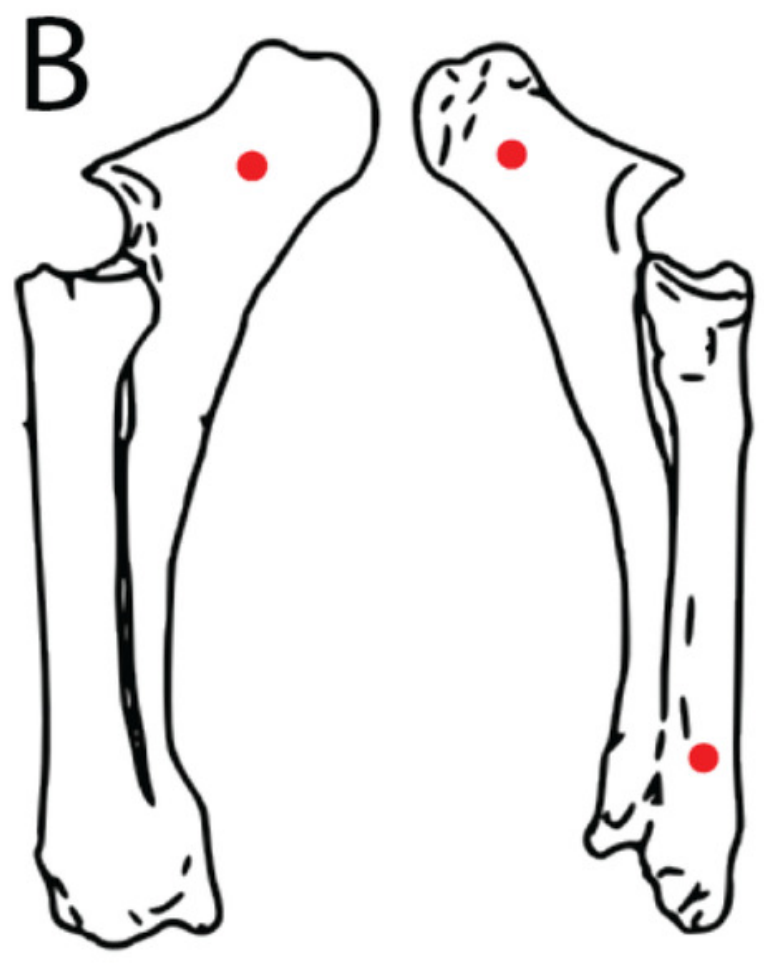


\section{Figure 5}

Computed tomographic image of bovine right humerus post-indentation.

Computed tomographic image of bovine right humerus post-indentation. Red arrows indicate location of experimental indentations.

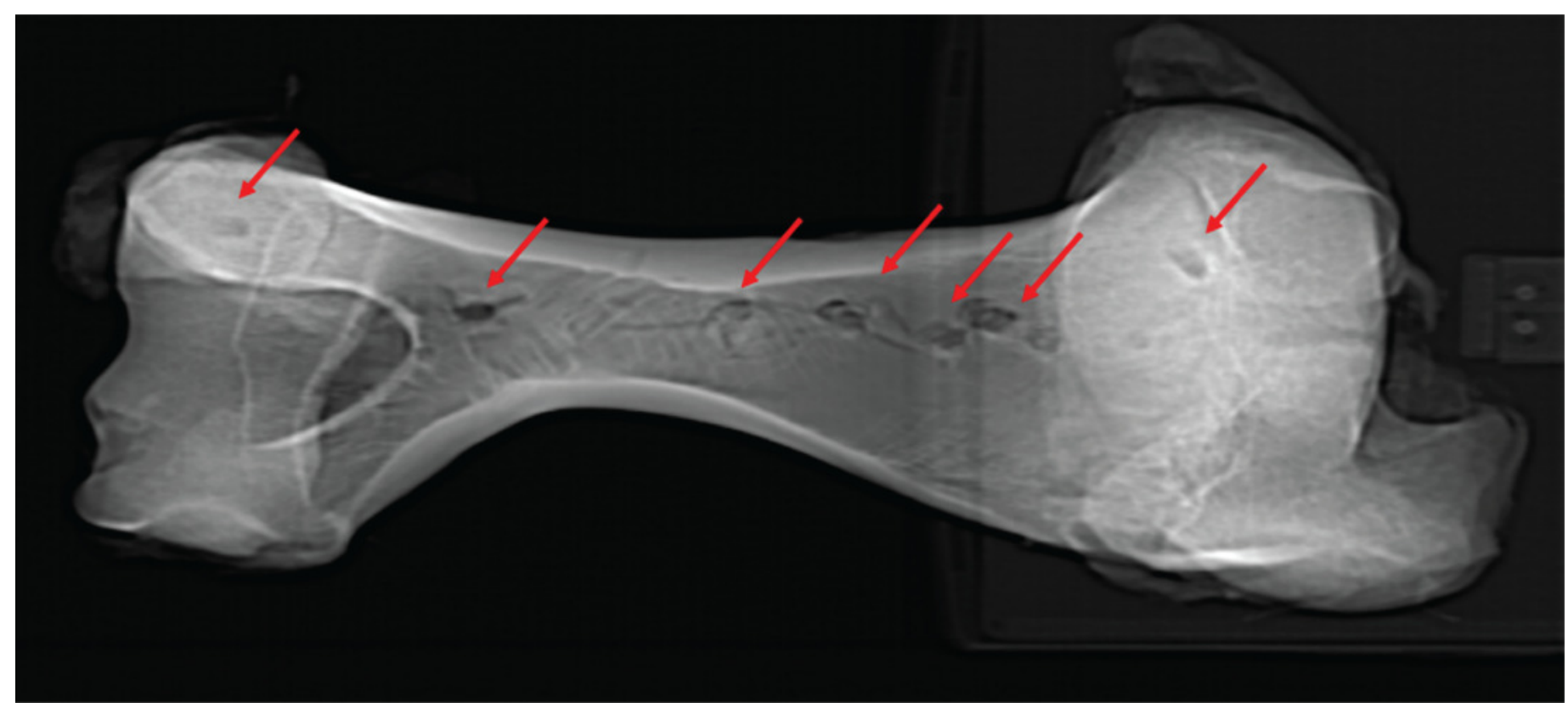




\section{Figure 6}

Indentation force-cortical thickness plots for experimental data.

Indentation force-cortical thickness plots for experimental data. Thick line represents the fitted linear regression line. Shaded region represents 95\% confidence intervals. (A) Analysis done using the full dataset that excluded trials with visible specimen movements. (Force $=$ $637.41 *$ Cortical Thickness $+860.62 ; \mathrm{R}_{2}=0.5361$ ); (B) Analysis excluding both indentation forces at or over the $10,000 \mathrm{~N}$ threshold, and those trials that showed evidence of fracture. (Force $=628.48 *$ Cortical-Thickness $\left.+555.72 ; \mathrm{R}_{2}=0.6346\right)$. 


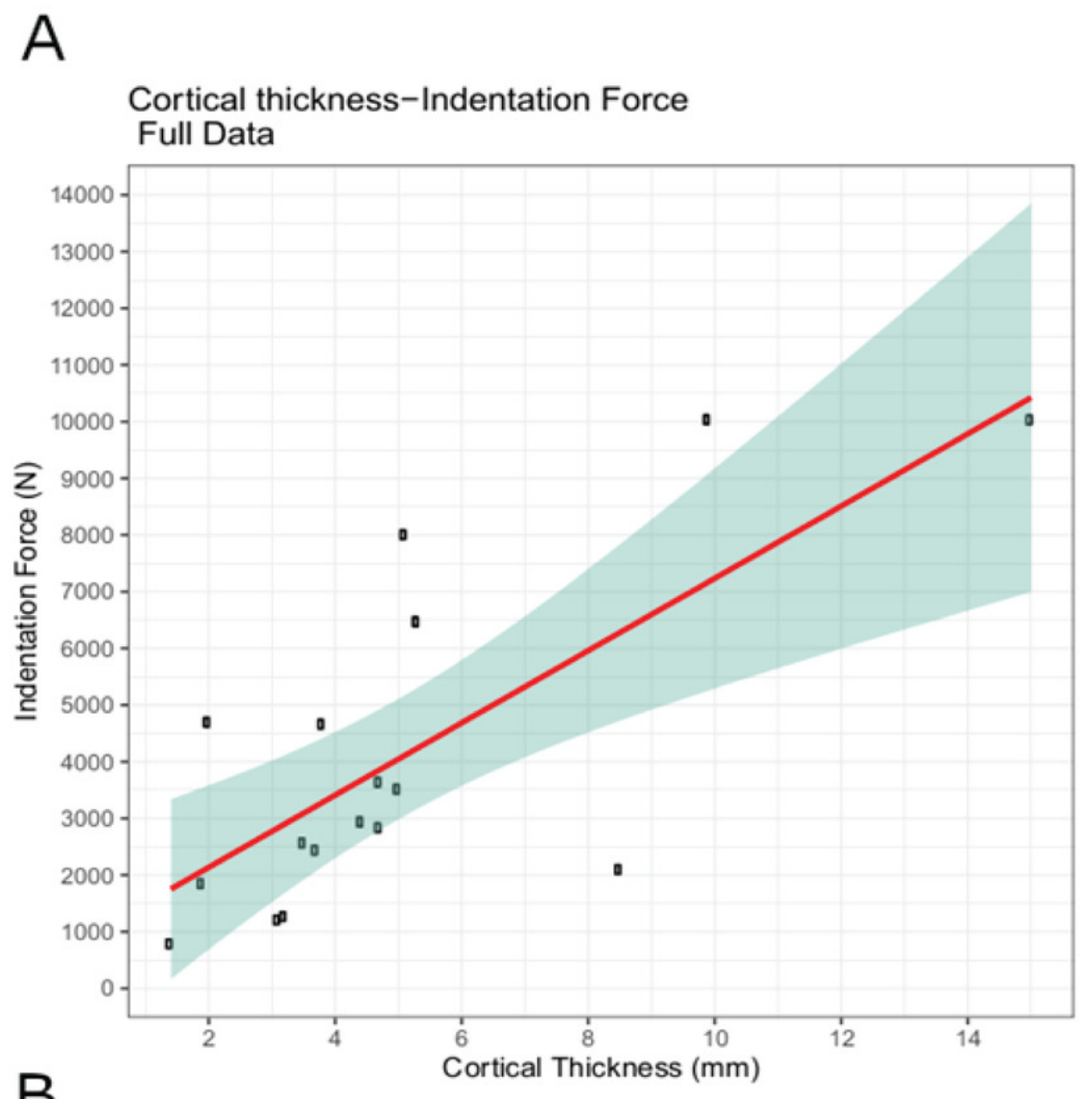

B

\section{Cortical thickness-Indentation Force} No Fractures

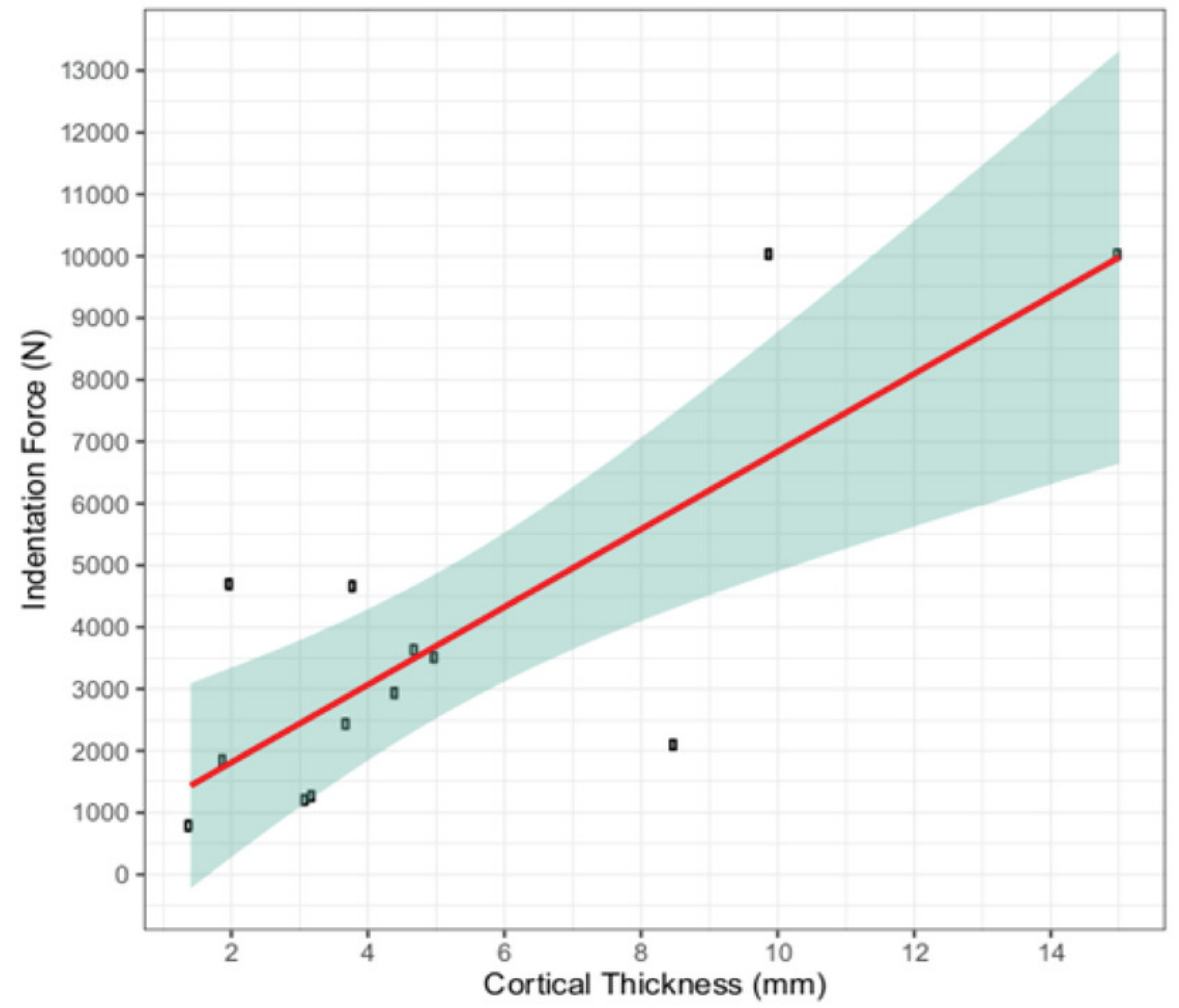

PeerJ reviewing PDF | (2021:03:58983:2:0:NEW 21 Apr 2021) 
Figure 7

Force-displacement curves from all experimental trials conducted in this study.

Force-displacement curves from all experimental trials conducted in this study. A typical smooth curve (a) exhibits no sudden drops, whereas curves indicative of fracture (b) show such drops.

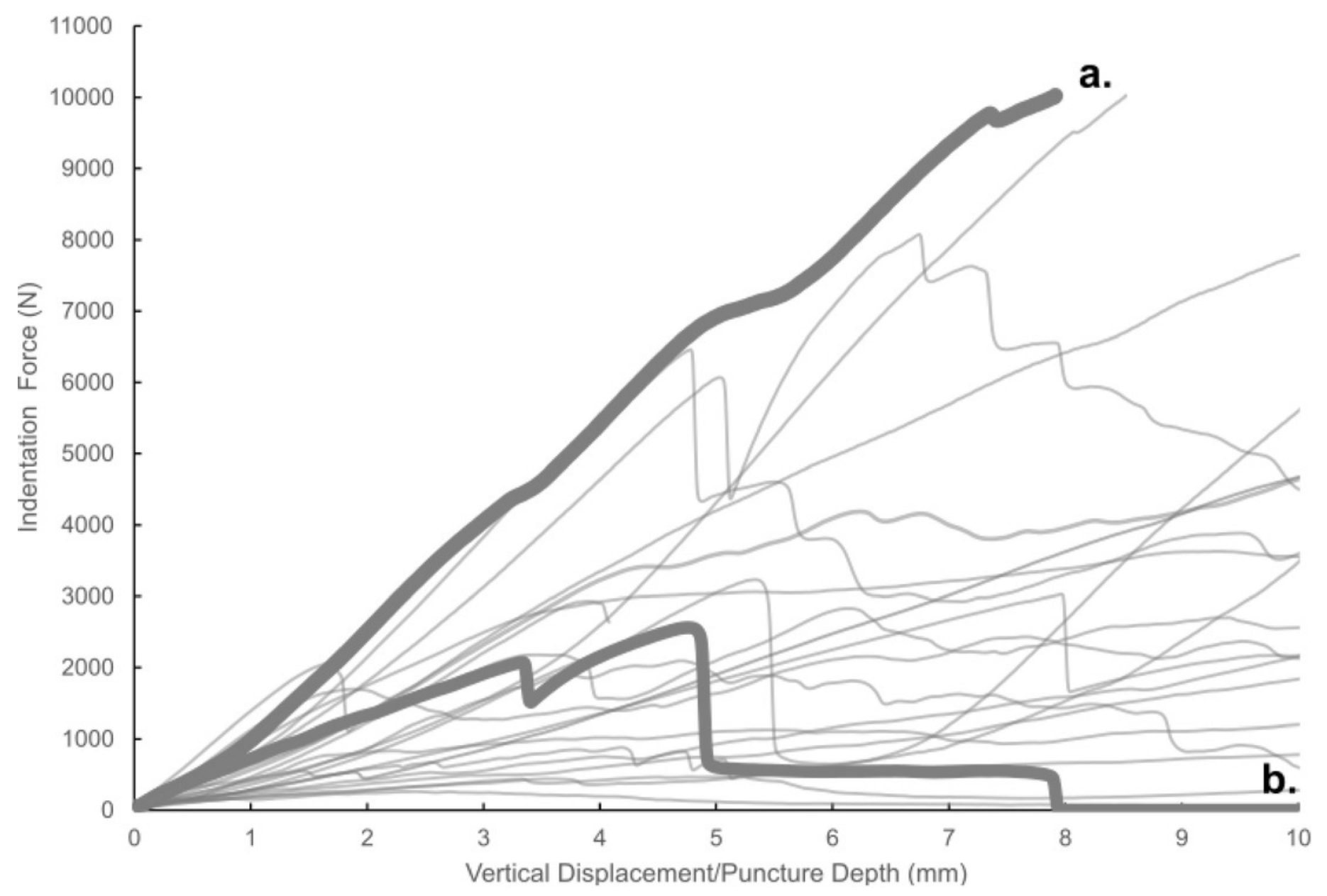




\section{Table $\mathbf{1}$ (on next page)}

Puncture dimensions $(\mathrm{mm})$, cortical thickness $(\mathrm{mm})$, and measured force $(\mathrm{N})$ of the 17 indentation trials. 
1 Table 1. Puncture dimensions ( $\mathrm{mm})$, cortical thickness $(\mathrm{mm})$, and measured force $(\mathrm{N})$ of the 17

2 indentation trials.

\begin{tabular}{|c|c|c|c|c|c|}
\hline \multicolumn{3}{|c|}{$\begin{array}{l}\text { Puncture Dimensions } \\
(\mathrm{mm})\end{array}$} & \multirow{2}{*}{\begin{tabular}{|c} 
Cortical Thickness \\
$(\mathrm{mm})$
\end{tabular}} & \multirow{2}{*}{$\begin{array}{c}\text { Force } \\
(\mathrm{N}) \\
\end{array}$} & \multirow[t]{2}{*}{ Fracture } \\
\hline Length & Width & Depth & & & \\
\hline 11 & 7.7 & 10 & 1.4 & 782.929 & No \\
\hline 7.3 & 5.7 & 10 & 1.9 & 1844.92 & No \\
\hline 9.5 & 8 & 10 & 2 & 4690.79 & No \\
\hline 10 & 8.1 & 10 & 3.1 & 1202.62 & No \\
\hline 6.9 & 5.2 & 6.8 & 3.2 & 1263.62 & No \\
\hline 6.7 & 4.1 & 1 & 3.5 & 2562.17 & Yes \\
\hline 8.8 & 5.2 & 10 & 3.7 & 2432.3 & No \\
\hline 10.4 & 5.4 & 10 & 3.8 & 4657.54 & No \\
\hline 2.8 & 3.7 & 4 & 4.42 & 2931 & No \\
\hline 8.3 & 5.7 & 10 & 4.7 & 2830.95 & Yes \\
\hline 8.4 & 5 & 10 & 4.7 & 3630.72 & No \\
\hline 9.3 & 5.3 & 10 & 5 & 3509 & No \\
\hline 8.8 & 5.3 & 10 & 5.1 & 8000 & Yes \\
\hline 8.5 & 5.6 & 10 & 5.3 & 6463.85 & Yes \\
\hline 11.9 & 3.8 & 4 & 8.5 & 2094.83 & No \\
\hline 6 & 3.4 & 8.5 & 9.9 & 10028.7 & No \\
\hline 5 & 5.6 & 7.9 & 15 & 10024.6 & No \\
\hline
\end{tabular}

3

4 